\title{
A Facile Activation Method for Improving the Wettability of Polyurethane Surfaces
}

\author{
LUIZA MADALINA GRADINARU1*, STELIAN VLAD ${ }^{1}$, MIOARA DROBOTA ${ }^{1}$, MARIA SPIRIDON ${ }^{1}$, IOAN ISTRATE ${ }^{2}$ \\ ${ }^{1}$ Petru Poni Institute of Macromolecular Chemistry, 41-A Grigore Ghica Voda Alley, 700487, Iasi, Romania \\ ${ }^{2}$ Polymer Adhesive Tapes SRL, 96-B Timisoara Blvd., Bucharest, Romania
}

\begin{abstract}
This work reports the activation of polyurethane film surfaces in order to enrich them with polar groups such as $-\mathrm{NH}_{2}, \mathrm{OH},-\mathrm{COOH}$ or radicals, which further allows immobilization of several bioactive compounds. UVactivation was used to introduce new groups on the polymer surface without affecting the bulk properties. The current arising species improve the wettability of the PU surfaces as it was observed from the static contact angle measurements. The structure and composition of the new PU surfaces were analyzed by using ATR-FTIR spectroscopy. The results suggested the possibility of modifying the PU surfaces in a shorter time periods, in order to provide many sites to attach other biomacromolecules by polar interaction or hydrogen bonding.
\end{abstract}

Keywords: polyurethane surfaces, UV-activation, wettability, bioactive compounds immobilization

Polyurethanes (PUs) are one of the most versatile and promising families of polymers because they can be prepared from a wide variety of materials with different properties leading to a high variety of applications. They offer the possibility to tailor the final properties through the variation in the compositions by changing the ratio of soft and hard segments. Thus, PUs have been extensively used in modern life, in different fields such as coatings, adhesives, packaging, furniture, automotive, textile etc. [1-3]. Moreover, they can be obtained in various forms, such as: films, foams, gels or nanofibers. Over the past decades, PUs have been used for several biomedical applications due to their good biocompatibility, biodegradability and mechanical properties [4]. There was also a high demand of PUs based materials in manufacturing of various implantable or extracorporeal medical devices, drug delivery systems, in tissue engineering, wound dressings, etc. [5-7].

When biomaterials come into contact with the body, the biological response is greatly dependent by the chemistry and structure of the material surfaces, and therefore, the functionality of a polymeric surface is of utmost importance. Generally, surface modification of polymers aims to tailor the surface characteristics of the material for a specific application without affecting the bulk properties. Several physical and chemical techniques have been developed to improve the surface wetting, leading to blood compatibility or cellular adhesion $[8,9]$. Among them, UV-treatment is one of the most suitable surface modification techniques to activate the polymeric surfaces because it exhibits several advantages, such as: low cost processing, simple equipment etc [2].

Various strategies have been developed, over the time, for polyurethane surfaces modification, because the first interaction of the biomaterials and living system is at the interface. Moreover, the blood compatibility of polymers is strongly influenced by chemical groups present at their surfaces [10]. As shown in literature, these methods involve surface modification and further grafting a hydrophilic component, such as poly(ethylene oxide) [11], 2hydroxyethylmethacrylate [12], peptides [13], or heparin [14].
During UV treatment, some bond scission of existing groups occur at the surface of polyurethane, creating new functional groups, such as $-\mathrm{NH}_{2},-\mathrm{OH}$, radicals etc $[15,16]$. These new species can further provide an anchor for attaching bioactive natural or synthetic compounds, like: proteins, peptides, enzymes or antimicrobial agents depending on the desired application.

The aim of this study was to increase the hydrophilicity/ wettability of PU surface using a facile method because the enriched polar groups on the polymer surface could provide many sites to immobilize different bioactive molecules by polar interaction and hydrogen bonding. In order to confirm the required modification at surface level, some indirect or direct methods are successful used for their characterization [17]. Two experimental techniques were chosen for the present study: Attenuated total reflectance-Fourier transform infrared (ATR-FTIR) and contactangles measurement. The firstone gives important information on composition and structure of PU surfaces and the second one provides quantitative information concerning the surface free energies. All the measurements were carried out before and after UV-treatment of the PU surfaces.

\section{Experimental part \\ Materials}

Poly(caprolactone) diol $\left(M_{n}=2000 \mathrm{Da}\right)$, poly $(1,4-$ butylene adipate) diol ( $\left.\mathrm{M}_{2}=2000 \mathrm{Da}\right), 1,4$-butanediol, dimethylformamide (DMF) and ethylene glycol were purchased from Sigma-Aldrich (Germany) and used as received. Methylenediphenyl 4,4'-diisocyanate was freshly distilled before synthesis. Other chemicals were of analytical grade and used without further purification.

\section{Preparation of PU films}

The synthesis method of this PU, using a two-step solution polymerization has been previously reported in detail $[15,16,18]$. Thus, the PUs was obtained from poly(caprolactone) diol and poly(1,4-butylene adipate) diol as soft segment, 1,4-butanediol as chain extender, and methylene diphenyl 4,4'-diisocyanate as hard segment. After polymer synthesis, the dried PU was redissolved in 
DMF at a concentration of $30 \%(w / w)$. The PU solution was degassed under vacuum (10-15 $\mathrm{mmHg}$ ) and then it was casted onto a glass slide using a doctor blade with a gap of $0.6 \mathrm{~mm}$. The films were precipitated in distilled water at $45^{\circ} \mathrm{C}$. The resulted PU films were intensively washed with distilled water and dried at room temperature and low pressure $(1-2 \mathrm{mmHg})$. The films were finally cut into rectangular shapes of $20 \times 60 \mathrm{~mm}$ and used for further modification.

\section{Surface modification}

The PU samples were activated in air at room temperature with a Herolab UV Analysis Lamp (Germany), Model: UV-8 S/L: 254/365 nm, UV tube type: je $1 \times 8$ W, Intensity: 680 (S)/950 (L) $\mu \mathrm{W} / \mathrm{cm}^{2}$. The distance between the samples and light source was kept constant at $20 \mathrm{~cm}$. The rectangular PU samples were UV-irradiated for different time points at 2, 4, 6 and $8 \mathrm{~h}$.

\section{Surface analysis}

\section{ATR-FTIR analysis}

Attenuated total reflectance-Fourier transform infrared (ATR-FTIR) spectra of the PU samples were recorded using a BrukerLUMOS - FT-IR Microscop (Germany) equipped with a diamond crystal with single reflection at $45^{\circ}$ angle and OPUS 8 spectral processing software. The sample surface was scanned in the 4000-600 $\mathrm{cm}^{-1}$ range, with a resolution of $2 \mathrm{~cm}^{-1}$. All ATR-FTIR spectra were recorded at room temperature.

\section{Static contact angle measurements}

Static contact angle measurements with the sessile dropmethod were recorded and analyzed at room temperature on a CAM-101 contact angle system from KSV Instruments (Finland). The contact angle system was equipped with a liquid dispenser, video camera, and dropshape analysis software. For this study, double distilled water and ethylene glycol were used as solvents. The reported contact angle values are the average of at least 3 measurements on differentregions of the surface, for each kind of liquid.

\section{Results and discussions \\ ATR-FTIR analysis}

The spectroscopic methods are key tools in determining the presence of functional groups on the polymeric surfaces. Thus, the UV-activation process was monitored by ATR-FTIR analysis and the spectra were collected before and after exposure to UV lightfor 2, 4, 6 and $8 \mathrm{~h}$, respectively.

The ATR-FTIR spectrum of non-irradiated PU shows the main absorption bands, characteristic of the PU structure: free $-\mathrm{NH}$ and $-\mathrm{OH}$ stretching vibrations $\left(3500 \mathrm{~cm}^{-1}\right)$, hydrogen-bonded $-\mathrm{NH}$ stretching vibrations $\left(3330 \mathrm{~cm}^{-1}\right)$, $\mathrm{C}-\mathrm{H}$ asymmetric and symmetric stretching $\left(2968 \mathrm{~cm}^{-1}\right.$ and $2856 \mathrm{~cm}^{-1}$ respectively), C=0 stretching (1727 and 1702 $\mathrm{cm}^{-1}$ ), and $\mathrm{C}-0-\mathrm{C}$ stretching (1223 and $1075 \mathrm{~cm}^{-1}$ ).

It is well known that the UV-irradiation affects the chemical structures of the PU surfaces at longer activation time, leading to degradation [19]. However, shorter UVirradiation time is a preferred method to activate the PU surface, in order to improve its wettability, providing further anchors for attaching some bioactive compounds, without reduction of polymer molar mass [20]. The mechanism is very complex and involves, as previously was shown, some cleavage of the urethane group (Photo-Fries rearrangement), photooxidation of the central $-\mathrm{CH}_{2}$ group flanked by aromatic rings, Norrish type mechanism, etc (fig. 1) $[15,16,19,21]$. Thus, after UV-irradiation several changes were noticed in the ATR-FTIR spectra (fig. 2).

UV treatment induced the appearance of some hydrophilic groups on the PU surfaces. Thus, the - $\mathrm{NH}$ and $\mathrm{C}=0$ groups from the PU structure display a fingerprints in important infrared regions because these groups can interact by inter-and intramolecular hydrogen bonding. The presence of the absorption bands in the $3700-3200 \mathrm{~cm}^{-1}$ region has been assigned to the $-\mathrm{OH}$ and $-\mathrm{NH}$ stretching vibration. The PU surfaces were characterized by a peak at around $3330 \mathrm{~cm}^{-1}$ due to the absorption of bonded N-H stretching vibration, which decreases with irradiation time.
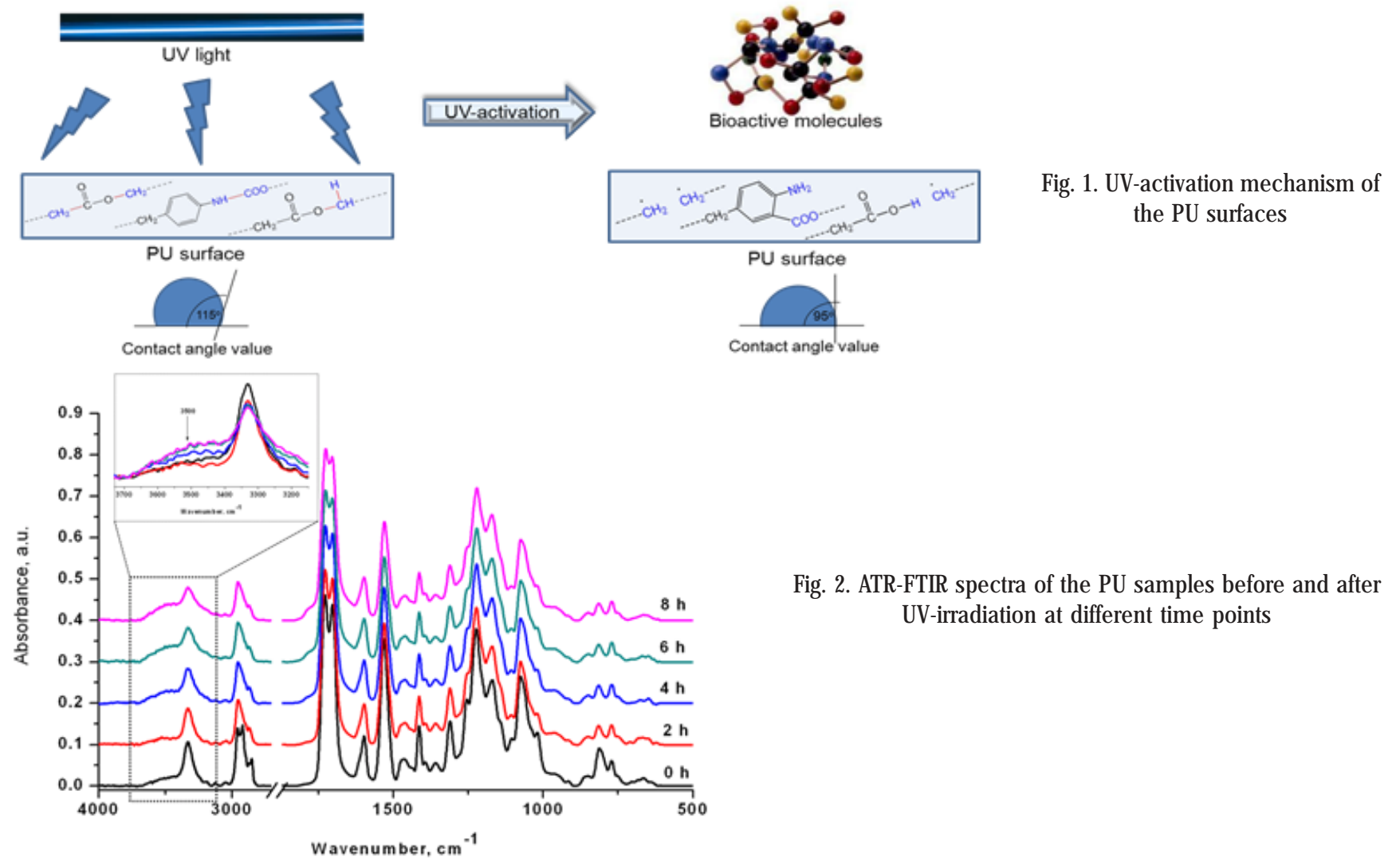

Fig. 2. ATR-FTIR spectra of the PU samples before and after UV-irradiation at different time points 
Atlonger exposure time the shoulder intensity, around 3500 $\mathrm{cm}^{-1}$, slightly increases as displayed in figure 2 . This peak corresponds to the free-hydrogen stretching vibrations of free - $\mathrm{NH}-\mathrm{COO}-,-\mathrm{NH}_{2}-,-\mathrm{OH}$ that arises after irradiation of PU surfaces and is the result of both Photo-Fries rearrangements of the urethane groups and photo oxidation of ester groups $[15,16]$.

The peaks at $2959 \mathrm{~cm}^{\prime 1}$ and $2854 \mathrm{~cm}^{-1}$ can be assigned to the asymmetric and symmetric $\mathrm{C}-\mathrm{H}$ stretching vibration of the $-\mathrm{CH}_{2}$ - groups.

Two peaks of carbonyl absorption can also be identified, which can be due to a free carbonyl stretching vibration at $1727 \mathrm{~cm}^{-1}$ and a hydrogen - bonded carbonyl at 1702 $\mathrm{cm}^{-1}$ (fig. 3). Moreover, a shoulder around $1781 \mathrm{~cm}^{-1}$, characteristic to the $\mathrm{C}=0$ stretching vibration of carboxyl groups was distinguished and increases with the irradiation time. These carboxyl groups are originated from the ester functional groups in the PU structure [22]. This is consistent with the broadening of the $-\mathrm{OH}$ stretching vibration from the $3500 \mathrm{~cm}^{-1}$.

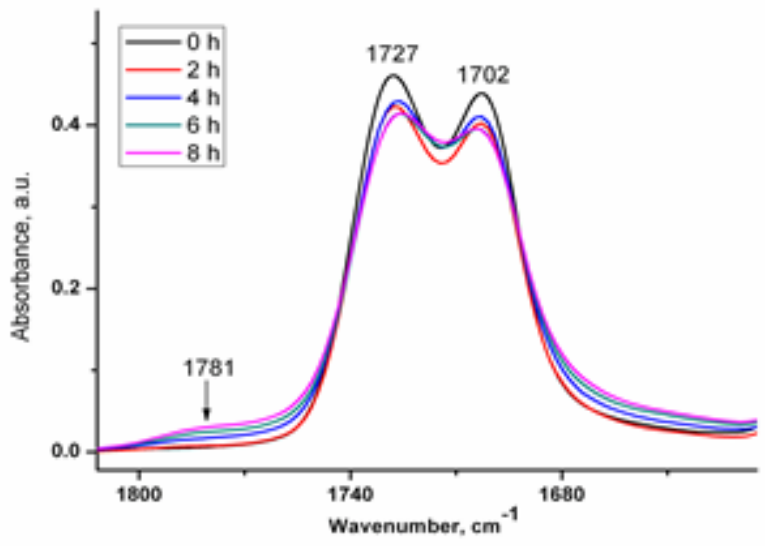

Fig. 3. ATR-FTIR spectra of the PU samples before and after UV-activation in the carbonyl region (1790-1680 $\mathrm{cm}^{-1}$ )

Like $-\mathrm{NH}$ region, the $\mathrm{C}=0$ stretching vibration region has a major concern because provides useful information on the mode of hydrogen bonding. The vibration band in the carbonyl region can be considered as a sum of peaks, obtained by its deconvolution, based on the Gaussian

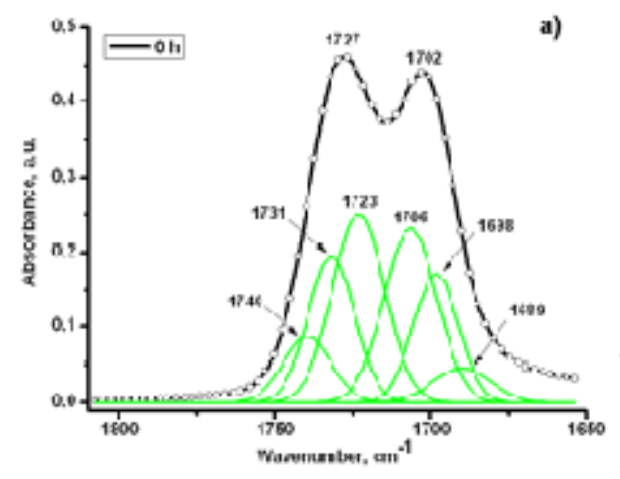

Fig. 4. The deconvolution of the carbonyl bands using Gauss method of

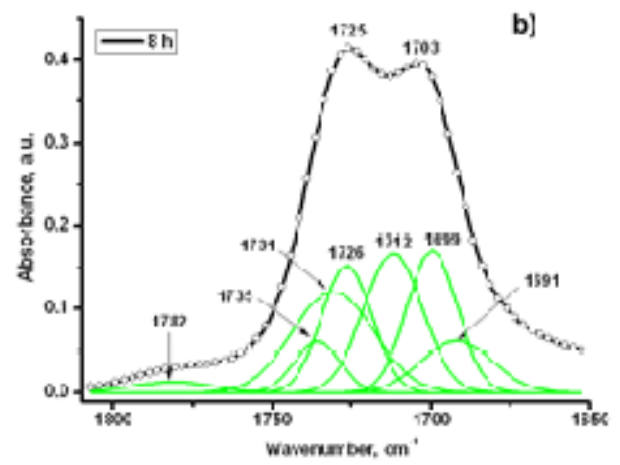

function. For example, the deconvolution spectra of the non-irradiated and 8h-activated PU sampleswere performed. For these samples different peaks varying in height, wavenumber and wavelength were resulted by deconvolution. Thus, the non-irradiated PU sample has the peaks maximum at 1740, 1731, 1723, 1706, 1698 and 1689 $\mathrm{cm}^{-1}$, respectively, whereas the 8hours activated PU sample at 1782, 1735, 1731, 1726, 1712, 1699 and $1691 \mathrm{~cm}^{-1}$, respectively. Therefore, the deconvolution peaks from the higher frequency are assigned to the free $\mathrm{C}=0$ stretching vibration and those from lower frequency are attributed to the $\mathrm{H}$-bonded $\mathrm{C}=0$ stretching vibration [23].

In figure 5 the ATR-FTIR spectra of PU samples before and after UV-irradiation, between 1600 and $600 \mathrm{~cm}^{-1}$ are presented. Generally, the PU structures are not stable to light and are susceptible to degradation when they are exposed to the UV radiation [24]. Thus, the signal at 1599 $\mathrm{cm}^{-1}$ is characteristic to the stretching vibration of the $\mathrm{C}=\mathrm{C}$ in the aromatic rings [25] and shows a tendency of decreasing with increase of the UV-exposure time. This phenomenon is due to the oxidation of the $-\mathrm{CH}_{2}-$ groups derived from the aromatic diisocyanate structures, leading to some conjugated quinone products $[19,24]$.

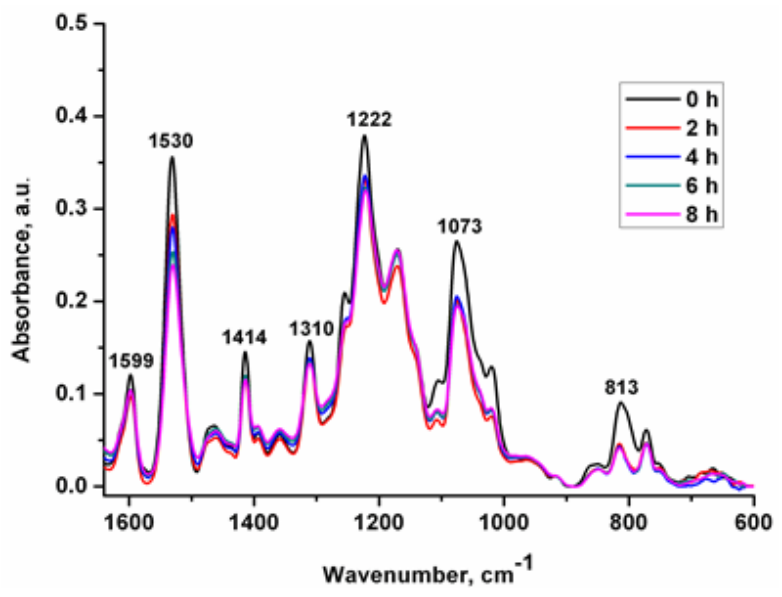

Fig. 5. ATR-FTIR spectra of the PU samples before and after UV-activation in the region $1600-600 \mathrm{~cm}^{-1}$

The absorbance at around $1530 \mathrm{~cm}^{-1}$ in the ATR-FTIR spectrum of PU sample could be attributed to the coupling of $\mathrm{N}-\mathrm{H}$ bending vibration with $\mathrm{C}-\mathrm{N}$ stretching vibration in the -C-NH group (amide II band) and is more complex than amide I [19]. The decrease in the absorbance region of the amide II indicates that some degradation have occurred in the urethane groups via a free radical mechanism [26] resulting in the appearance of some radicals that could later interact with bioactive molecules. The peak at $1414 \mathrm{~cm}^{-1}$ is due to the symmetric bent vibration of the $-\mathrm{CH}_{2}$ - groups derived from the polyester structures used in PU synthesis.

The absorption band at $1310 \mathrm{~cm}^{-1}$ corresponds to the combination of $\mathrm{N}-\mathrm{H}$ bending vibration and $\mathrm{C}-\mathrm{N}$ stretching vibration (amide III band). Between $1300-1100 \mathrm{~cm}^{-1}$ are the bands characteristic to the $\mathrm{C}-\mathrm{O}$ stretching vibrations in esters. The stretching vibration of $\mathrm{C}-\mathrm{O}-\mathrm{C}$ groups from the urethane structures can be observed at $1073 \mathrm{~cm}^{-1}$ and the symmetric stretching vibration at $1022 \mathrm{~cm}^{-1}$.

Finally, the finger print infrared region between 900-600 $\mathrm{cm}^{-1}$ was investigated. The UV-irradiated PU samples display a decrease of the bands centered at 856, 813, 772 and $664 \mathrm{~cm}^{-1}$, respectively, corresponding to the aromatic $\mathrm{C}$-H out-of-plane or in-plane deformation vibration in $p$ disubstituted rings [21, 27]. 


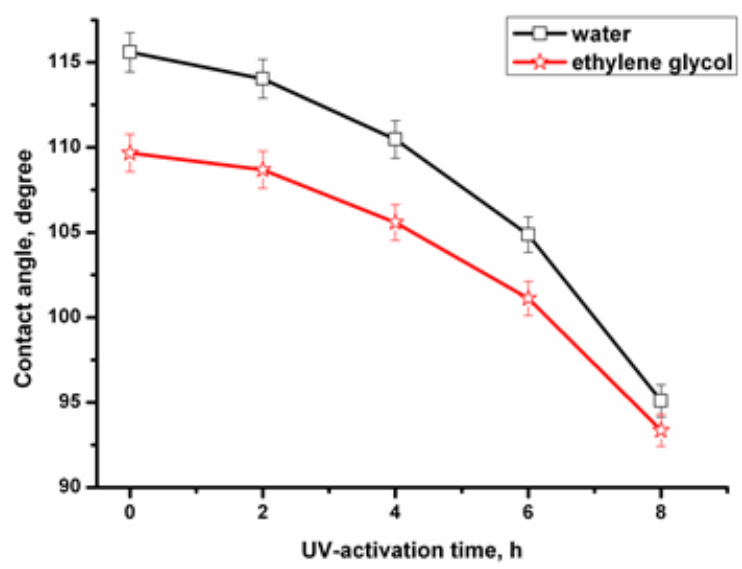

Fig. 6. Contact angle values of PU sample surfaces as a function of UV-activation time

Water contact angle and surface energy measurements

The wettability and surface energy measurements of the polymeric surfaces are important parameters that could influence the cellular adhesion and biocompatibility, since the interaction between blood and biomaterials occurs at the interface [28]. In order to determine the wettability of the polyurethane samples, the static contact angle of each sample was measured. Generally, the measurement of contact angles isconsidered the most convenient and simplest method for characterizing the surface properties of the solid samples. This technique gives us information about the interactions between the chemical groups from the solid sample surface ofinterest and liquids with well determined surface tensions. It is widely recognized that the contact angle is the angle formed between the baseline and the tangent to the drop at the three-phase point $[29,30]$. This value is specific for any system being determined by the interactions of the three interfaces and can be described by Young's equation:

$$
\gamma_{L v} \cos \theta=\gamma_{s v}-\gamma_{s L}
$$

where: $\gamma_{S V}$ is the energy of surface, $\gamma_{S L}$ is the solid - drop interfacial tension, $\gamma_{L V}$ is the liquid-vapor surface tension and $\cos \theta$ is the drop - surface contact angle [29-31].

Figure 6 shows the average contact angles data of PU films before and after UV-activation. The PU film before UV-activation exhibited an average contact angle of $115^{\circ}$, suggesting that PU surface is hydrophobic. After $2 \mathrm{~h}$ of UVactivation of PU surfaces, the contact angle decreased to $114^{\circ}$, and further decreased after $8 \mathrm{~h}$ of irradiation until $95^{\circ}$. The increase in hydrophilicity and better wettability behavior of the $8 \mathrm{hUV}$-irradiated PU surface compared to untreated PU are attributed to a complex reaction mechanism like Photo-Fries rearrangement of the urethane groups or Norrish I reaction [15, 16]. Therefore, after UV-irradiation, the PU surfaces become hydrophilic due to the arising of some polar groups such as $-\mathrm{NH}_{2},-\mathrm{OH}$, -COOH etc. (fig. 1), as will be further seen in calculation of polar component of free energy. These polar groups on the PU surfaces determine an increase of the hydrogen bounding interactions and therefore the contact angle values decreases [32]. Furthermore, these results are in accordance with those obtained by ATR-FTIR analysis. The same decreasing trend was observed when the contact angle was determined in ethylene glycol.

The surface energy values $\left(\gamma_{\mathrm{cy}}\right)$, which were determined according to Owens-Wendt-Rabel and Kaelbe method [29, $33,34]$ using the obtained contact angle values, are illustrated in table 1. According to this method, the surface
Table 1

SURFACE PARAMETERS VALUES OF PU SAMPLES BEFORE AND AFTER UV-IRRADIATION

\begin{tabular}{|c|c|c|c|c|c|}
\hline $\begin{array}{c}\text { Sample } \\
\text { time } \\
\text { points }\end{array}$ & $\underset{(\mathrm{mN} / \mathrm{m})}{W_{\mathrm{a}}}$ & $\begin{array}{c}\gamma \mathrm{sV} \\
(\mathrm{mN} / \mathrm{m})\end{array}$ & $\begin{array}{c}\gamma^{\mathrm{P} S \mathrm{SV}} \\
(\mathrm{mN} / \mathrm{m})\end{array}$ & $\begin{array}{c}\gamma^{\mathrm{d}} \mathrm{sv} \\
(\mathrm{mN} / \mathrm{m})\end{array}$ & $\underset{(\mathrm{mN} / \mathrm{m})}{\gamma \mathrm{SL}}$ \\
\hline $0 \mathrm{~h}$ & 41.34 & 5.87 & 4.17 & 1.69 & 37.32 \\
\hline $2 \mathrm{hrs}$ & 43.13 & 6.42 & 4.88 & 1.53 & 36.08 \\
\hline $4 \mathrm{hrs}$ & 47.33 & 7.81 & 6.32 & 1.49 & 33.28 \\
\hline $6 \mathrm{hrs}$ & 53.98 & 10.50 & 9.20 & 1.30 & 29.31 \\
\hline $8 \mathrm{hrs}$ & 66.33 & 17.17 & 16.31 & 0.85 & 23.63 \\
\hline
\end{tabular}

free energy can be divided in two fractions: polar $\left(\gamma_{\mathrm{sy}}^{\mathrm{p}}\right)$ and dispersive $\left(\gamma^{d}\right)$ fractions. The polar component includes two types of Coulomb interactions: dipole-dipole and dipole-induced dipole, and the dispersive component represent van der Waals interactions [30]. It is also well know that the hydrogen bonding is one of the components of the polar fraction which contributes to the surface free energy of a material, or the interfacial free energy between materials [28]. The results reveal that the total surface energy of the modified PU surfaces increases from 5.87 $\mathrm{mN} / \mathrm{m}$ for the unmodified surface, to $17.17 \mathrm{mN} / \mathrm{m}$ after $8 \mathrm{~h}$ of UV-irradiation. Moreover, the obtained results for the surface energy components presented in Table 1 showed an increase of the polar component of the surface energy from $4.17 \mathrm{mN} / \mathrm{m}$ to $16.31 \mathrm{mN} / \mathrm{m}$ when film surfaces are UV-irradiated for 8 hours. In this way, polar groups are introduced on the surface, and as a consequence, the surface free energy increased.

The work of adhesion $\left(W_{a}\right)$, determined with the previous method, reflects the wettability of the surface. Thus, the values of the work of adhesion are increased with the UV-irradiation time, while the values of their contact angle decrease.

The interfacial solid-liquid tension ( $\tilde{\gamma}_{\gamma_{S}}$ ) values decrease with decreasing contact angle values. These values could be high or low, depending on the attractive forces between molecules of the liquid and solid [28].

\section{Conclusions}

The results presented in this work suggest that the modification of PU surfaces by using UV-irradiation may be obtained without affecting the bulk properties. The UVtreatment of the PU surfaces, in a shorter time of irradiation, results in breaking of chemical bonds and generation of new functional groups on the surface which can be controlled by the irradiation time. These new groups are generally polar groups, such as $-\mathrm{NH}_{2},-\mathrm{OH}$, -COOH etc., that could provide sites to immobilize proteins or other molecules by polar interaction or hydrogen bonding. UVactivation process was monitored by ATR-FTIR spectroscopy which is a key tool in determining the presence of functional groups on the PU surfaces. Moreover, the UV-modifications induced an increase of hydrophilicity which was evaluated by static contact angle measurements, a convenient and simple method of surface analysis. The wettability and surface energy measurements of the PU surfaces are important parameters that could influence the cellular adhesion and biocompatibility. In conclusion, this method was proven to be a suitable surface modification technique to activate the PU films in order to enhance the biomacromolecules absorption.

Acknowledgements: The authors acknowledge the financial support of this research through the Project Partnerships for knowledge transfer in the field of polymer materials used in biomedical engineering ID P_40_443, Contract no. 86/8.09.2016, SMIS 105689, co- 
financed by the European Regional Development Fund by the Competitiveness Operational Programme2014-2020, Axis 1 Research, Technological Development and Innovation in support of economic competitiveness and business development, Action 1.2.3 Knowledge Transfer Partnerships.

\section{References}

1. AKINDOYO, J.O., BEG, M.D.H., GHAZALI, S., ISLAM, M.R., JEYARATNAM, N. YUVARAJ, A.R., RSC Adv., 6, 2016, p. 114453.

2. ALVES, P., FERREIRA, P., GIL, M.H., Polyurethane: Properties, Structure and Applications, Cavaco, L. I., Melo, J. A. (Ed.), Nova Publishers, 2012, p. 25.

3. SOMARATHNA, H.M.C., RAMAN, S.N., MOHOTTI, D., MUTALIB, A.A., BADRI, K. H., Constr. Build. Mater., 190, 2018, p. 995.

4. KHATOON, H., AHMAD, S., Significances Bioeng. Biosci., 2, 2018, 000536.

5. SHELKE, N.B., NAGARALE, R.K., KUMBAR, S.G., Natural and synthetic biomedical polymers, Kumbar, S.G., Laurencin, C.T., Deng, M. (Ed.), Elsevier, Amsterdam, 2014, p. 123.

6. WANG, W., WANG. C., The design and manufacture of medical devices, Woodhead Publishing, 2012, p. 115.

7. CITU, I.M., BORCAN, F., ZAMBORI, C., TITA, B., PAUNESCU, V., ARDELEAN, S., Rev. Chim. (Bucharest), 66, no.1, 2015, p. 119.

8. PRAKASH, S., KARACOR, M.B., BANERJEE, S., Surf. Sci. Rep., 64, 2009, p. 233.

9. THEVENOT, P., HU, W., TANG, L., Curr. Top. Med. Chem., 8, 2008, p. 270.

10.VENDRA, V.K., WU, L., KRISHNAN, S., Nanomaterials for the life sciences: Nanostructure thin films and surfaces, Kumar, C.S.R. (Ed.), WILEY-VCH Verlag Gmbh, Weinheim, 2010.

11. ZHOU, X., ZHANG, T., GUO, D., GU, N., Colloids Surf. A: Physicochem. Eng. Aspects, 441, 2014, p. 34.

12. ALVES, P., CARDOSO, R., CORREIA, T.R., ANTUNES, B.P., CORREIA, I. ., FERREIRA, P., Colloids Surf. B Biointerfaces 113, 2014, p. 25.

13. BUTRUK, B., BABIK, P., MARCZAK, B., CIACH, T., Procedia Eng., 59, 2013, p. 126.

14. MAROIS, Y., GUIDOIN, R., Madame Curie Bioscience Database, Landes Bioscience, Austin(TX), https://www.ncbi.nlm.nih.gov/books/ NBK64222000.
15. CIOBANU, C., GRADINARU, L. M., GRADINARU, R. V., DROBOTA, M., VLAD, S., Dig. J. Nanomater. Biostruct., 6, 2011, p. 1751.

16. CIOBANU, C., GRADINARU, L. M., GRADINARU, R. V., VLAD, S., Dig. J. Nanomater. Biostruct., 7, 2012, p. 97.

17. KLEE, D., HOCKER, H., Advances in Polymer Science, SpringerVerlag, Berlin Heidelberg, 2000.

18. VLAD, S., CIOBANU, C., GRADINARU, R. V., GRADINARU, L. M., NISTOR, A., Dig. J. Nanomater. Biostruct., 6, 2011, p. 921.

19. ROSU, D., CIOBANU, C., ROSU, L., TEACA, C. A., Appl. Surf. Sci., 255, 2009, p. 9453

20. HE, D., SUSANTO, H., ULBRICHT, M., Prog. Polym. Sci., 34, 2009, p. 62.

21. IRUSTA, L., FERNANDEZ-BERRIDI, M.J., Polymer, 40, 1999, p. 4821. 22. LUDWICK, A., AGLAN, H., ABDALLA, M.O., CALHOUN, M., J . Appl. Polym. Sci., 110, 2008, p. 712.

23.COLEMAN, M.M., LEE, K.H., SKROVANEK, D.J., PAINTER, P.C., Macromolecules, 19, 1986, p. 2149.

24. NEWMAN, C.R., FORCINITI, D., Ind. Eng. Chem. Res., 40, 2001, p. 3346.

25. WU, L., LI, D., YOU, B., QIAN, F., Int. J. Polym. Anal. Charact., 5, 2000, p. 491.

26. SAAD, G.R., KHALIL, M.T., SABAA, M.W., J. Polym. Res., 17, 2010, p. 33.

27. TANG, Q., GAO, K., Int. J. Polym. Anal. Charact., 22, 2017, p. 569.

28. MENZIES, K.L., J ONES, L., Optom. Vis. Sci., 87, 2010, p. 387.

29. ERBIL, H.Y., Surface Chemistry of Solid and Liquid Interfaces, Erbil, H.Y. (Ed.), Blackwell Publishing, England, 2006

30. MITTAL, K.L., Contact Angle, Wettability and Adhesion, Mittal, K.L. (Ed.), VSP, Boston, 2002.

31. KUANG, P., LEE, J.-H., KIM, C.-H., HO, K.-M., CONSTANT, K., J. Appl. Polym. Sci., 118, 2010, p. 3024.

32. ALVES, P., COELHO, J.F.J., HAACK, J., ROTA, A., BRUININK, A., GIL, M.H., Eur. Polym. J ., 45, 2009, p. 1412.

33. STAMM, M.,Polymer Surfaces and Interfaces. Characterization, Modification and Applications, Springer, Berlin, 2008.

34. SPERLING, L.H., Introduction to Physical Polymer Science, WileyInterscience, England, 2005

$\overline{\text { Manuscript received: } 10.02 .2019}$ 